\title{
The Use of GIS for Evaluating Areas From Someș Mic Meadow Affected by Excess Moisture
}

\author{
Tudor SĂLĂGEAN ${ }^{*}$, Teodor RUSU ${ }^{1}$,Lucian DRAGOMIR ${ }^{2}$, Paula Ioana MORARU ${ }^{1}$, Adrian Ioan POP ${ }^{1}$, Bog- \\ dan DUDA ${ }^{1}$ \\ 1) Faculty of Agriculture, University of Agricultural Science and Veterinary Medicine, Calea Mănăştur \\ 3-5, 400372, Cluj-Napoca, Romania; \\ ${ }^{2)}$ Faculty of Agriculture, Banat University of Agricultural Sciences and Veterinary Medicine Timişoara, \\ Calea Aradului 119, 300645, Timişoara, Romania; \\ * corresponding author: tudor.salagean@usamvcluj.ro
}

Bulletin USAMV series Agriculture 71(2)/2014

Print ISSN 1843-5246; Electronic ISSN 1843-5386

DOI 10.15835/buasvmcn-agr: 10309

\begin{abstract}
The area taken into study is located in the Transylvanian-Somes depression which is individualized compared to the surrounding regions from the morphological point of view, with hills and broad valleys accompanied by terraces. In lithological terms, there are present the sedimentary rocks, especially clays, marls, sands, sandstones and limestones. The area has a relatively dense population and has many settlements, roads, crops, etc. The main objective of this work is the use of geographic information systems to obtain a comprehensive database to assist in the creation of thematic maps of the Somes Mic floodplain (drainage direction map, soil map etc.), maps that are useful in agriculture and can be continually updated to reflect the current situation in the field. In order to obtain these thematic maps was necessary to create the primary database by entering the data into the computer from existing cartographic products. These data were entered in numerical form by scanning them at the specific scale. The data necessary for creating these thematic maps were collected from topographic maps, soil maps and the geological map containing the area of interest. For achieveing the objectives of this paper were conducted the following steps: making the spatial support through scanning, georeferencing spatial support, vectorization of the spatial support, creating the alphanumeric database and at the end elaborating thematic maps for the area thaken into study.
\end{abstract}

Keywords: GIS, thematic maps, excess moisture, floodplain, soil

\section{INTRODUCTION}

Soils degraded by excessive moisture are characterized by the content on surface and in the mass of water which prevents normal function of plants and bring soil in poor condition of tillage and cultivation (Dîrja and Budiu, 2006). A special case of excess water is the floods caused by overflowing rivers.

Canarache A. (1990), cited by Popescu and Bucur (2004) show that the limits of variation of the three phases of soils in Romania are: the solid $45-60 \%, 15-35 \%$ water and $5-40 \%$ air , for the normal development of the crop being required a minimum amount of air in the soil in the range of $10-20 \%$ of the apparent volume of the soil.
Humus contains 58\% carbon and 5\% nitrogen (Păcurar and Buta 2007) is the component that prints soil fertility traits, serving to improve soil structure by improving aero-hydric regime, since one gram of humus can retain 3-5 grams of water, being found in $80 \%$ of the total of $5 \%$ organic material from soil, the rest of the organic volume is occupied $10 \%$ of roots and $10 \%$ of biological organisms (Pidwirny, 2010).

If the limit wind suction of $1 / 3$ atmosphere is exceeded, respectively lower than 0.33 atm in the function of soil texture, or the amount of water exceeds the capacity of the water in field, the soil has excess moisture, are possible hydromorphic phenomena, such as pseudo-gleisation (Legin et al., 2007; Oncu and Bilaşcu, 2010). 
Excess water in the soil or on the surface have negative economic effects, being affected the production both quantitatively and qualitatively, these issues are highlighted by Moga et al. (2007).

GIS has a wide range of possible applications at national and local level. According M.V.K. Sivakumar and Donald E. Hinsman from the Division of Agricultural Meteorology, Satellite Activities Office and World Meteorological Organization, geographic data can help agricultural planners in deciding factors such as the best places for a particular culture, combining data on soils, topography and rainfall to determine the size and location of areas suitable biological. It can also provide information on issues such as land ownership, transportation, infrastructure, labor availability, distance to market centers and mapping degraded lands (Păcurar et al., 2013).

Accurateand timely information on agriculture is essential to the practice of sustainable agriculture (Guș and Rusu, 2011). This information can be classified into three groups: information on the current situation (eg. the current pattern of harvest, crop condition, soil degradation, land use etc.), information on changes occurring in agriculture and their rates and information on the future long-term effects.

In order to analyze any cartographic product is important to know the projection system of each map. Following on how the sizes are preserved, we can distinguish four types of projections: conform, equivalent, equidistant and azimuthal (Munteanu, 2003; Palamariu, 2004).

All Geographic Information Systems have as main support a spatial database that brings together the graphic information (coordinate systems, which are positioned relative to various reference systems etc.) and an alphanumeric database (table) which contains the attributes for the graphic elements (Dimitriu, 2007; Imbroane and Moore, 1999).

The purpose of this paper is to create a geographical informational system with which we can create different thematic maps necessary for developing management strategies and management of land improvement works for an efficiently use of water resources.

\section{MATERIALS AND METHODS}

The main purpose of a GIS is, besides entrying, storaging and editing of data (geographic, climatic, demographic, environmental etc.), studying and analyzing this information in a relational context, thus being able to develop some complex decisions (Dimitriu, 2007).

Geographic Information Systems are built around four basic elements or functions (Borşan and Voicu, 2009): designing the database; introducing the data; data interrogation; displaying the results.

For achieving these studies were conducted: making the spatial support through scanning; georeferencing spatial support; vectorization of the spatial support; creating the alphanumeric database; elaborating thematic maps for the area thaken into study.

In order to achieve the primary database, the first step was represented by data input from the cartographic products into computer in a numerical form by scanning them at a specific scale, and after that imported into ArcMap.

\section{RESULTS AND DISCUSSIONS}

For this paper were scanned and added to ArcMap the topographic maps at the sale of $1: 25.000$, the soil maps and the geological map containing the study area (Fig.1).

Georeferencing trapezoid sheets 1:25,000, 1977 Gauss-Kruger cylinder projection, Pulkovo 1942 datum. First is inserted the scanned map to be spatially referenced and after that there are created the pyramids.

\section{Following steps:}

Selecting the coordinate system in ArcMap from the Data Frame's properties and is chosen the projection - Gauss Kruger - Pulkovo 1942 GK zone 4N (Fig. 2).

Aligning and data transforming: this process involves identifying the set of control points whose coordinates are known (Fig. 3 and Fig. 4) and which must be determined with high accuracy, being dotted the pixel which locates point. The $\mathrm{x}$ and y coordinates of all other points on the map are calculated automatically based on algorithms from the program. Once there are determined the checkpoints of the map is very important to check if they are within tolerances.

After georeferencing each trapezoid will obtain the map of the studied area, but since the projection system specific to Romania is the 1970 


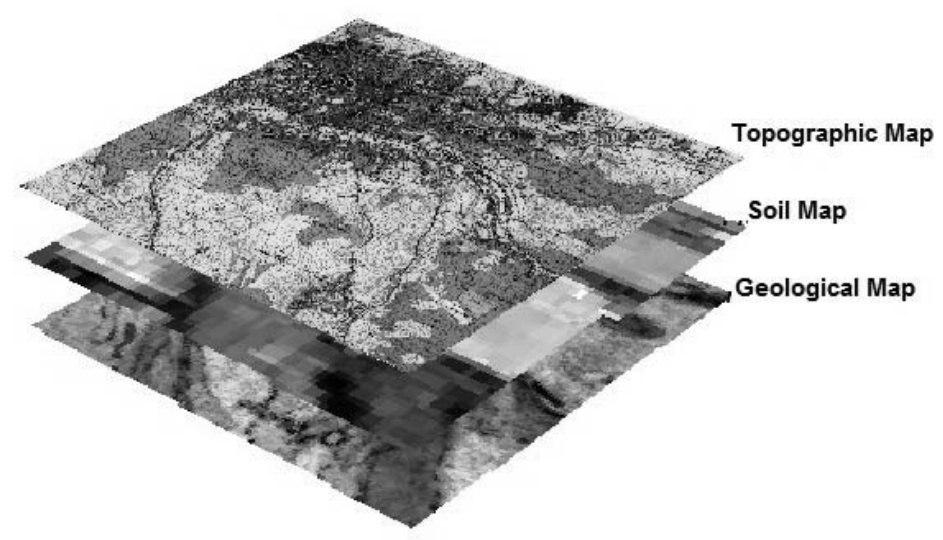

Fig. 1. Maps used for the GIS database

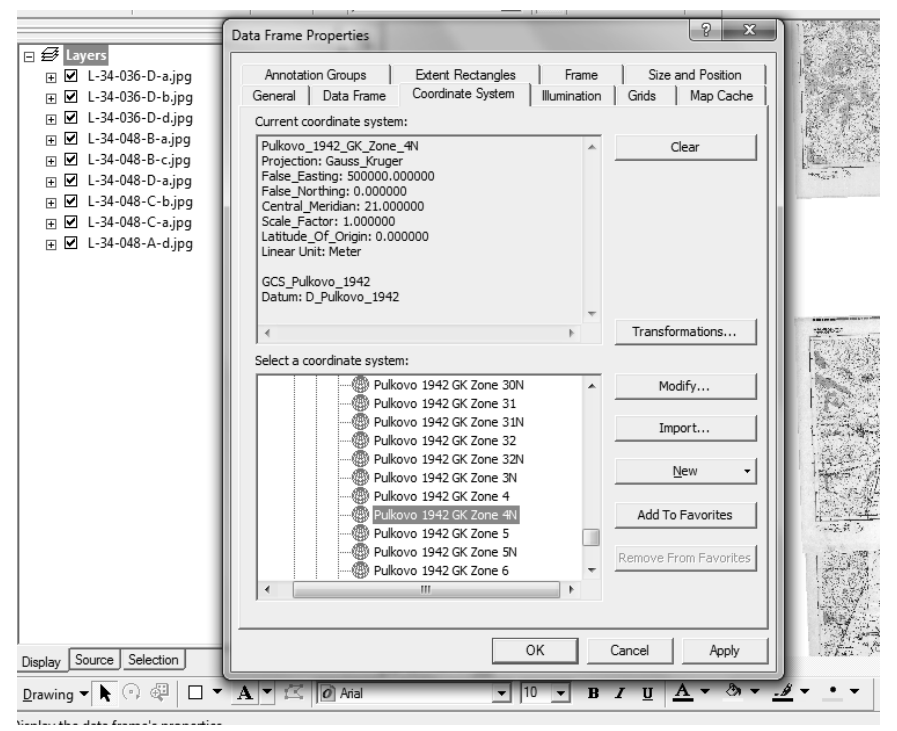

Fig. 2. Allocation of Gauss-Kruger system

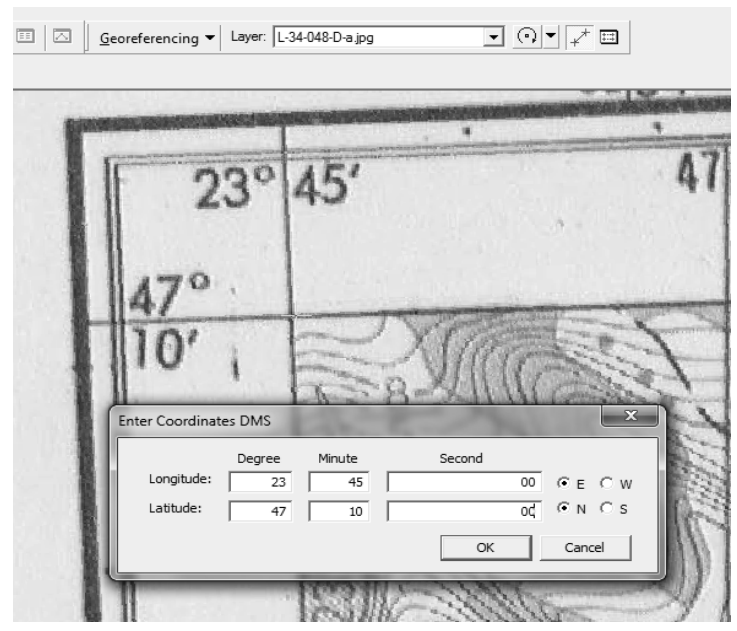

Fig. 3. Identifying and entering the coordinates

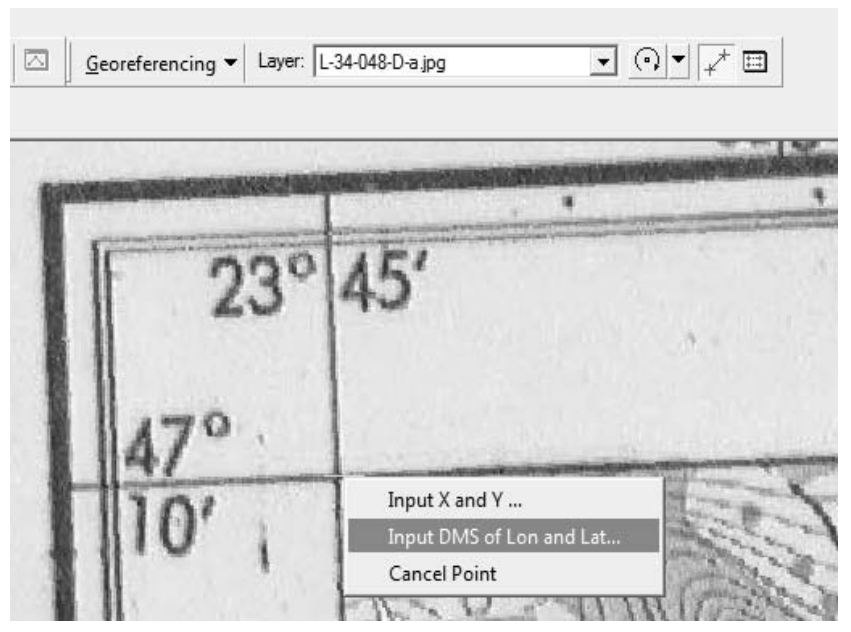

Fig. 4. Checking the control points in table of control points 
Stereographic Projection, it is necessary the transcalculus from the Gauss Kruger system.

The transcalculus is done in ArcToolbox (Fig. 5), which is an application integrated into ArcMap by ESRI (Environmental Systems Research Institute).

After realizing the transcalculus, the next step was to digitize the necessary elements from the cartographic products such as levelling contours, localities etc. Based on the digitized levelling contours was made a graphical representation of Someş Mic Valley from the studied area (Fig. 6).

An important factor influencing the excess moisture from the soil surface and from the soil, is the air temperature. So based on the data collected from the meteorological station in Cluj-Napoca, was performed an analysis of the average (Fig. 7), minimum (Fig. 8) and maximum (Fig. 9) monthly temperature values during the period 2011-2012.

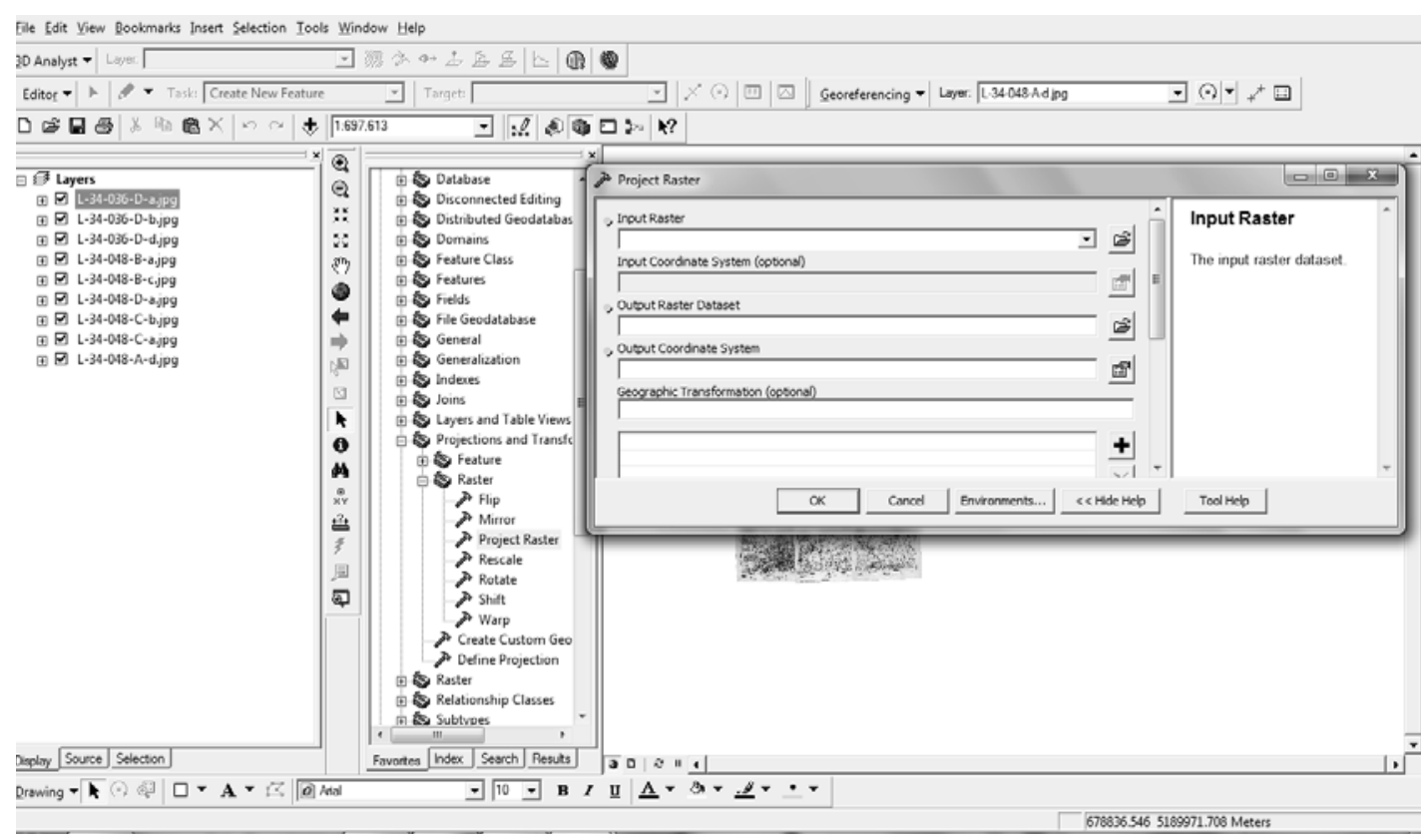

Fig. 5. Transcalculation from Gauss Kruger projection system into Stereographic 1970

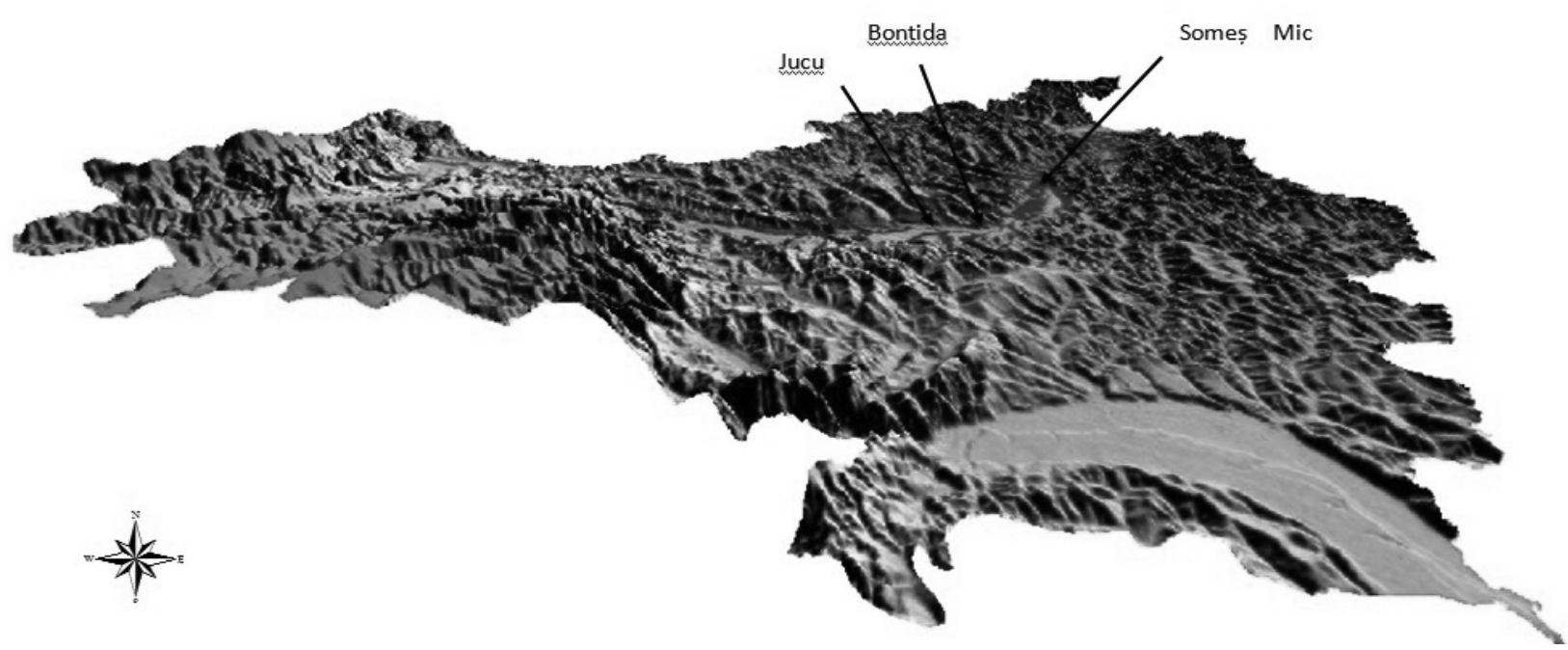

Fig. 6. Graphical representation of Someș Mic Valley between Cluj-Napoca and Dej 


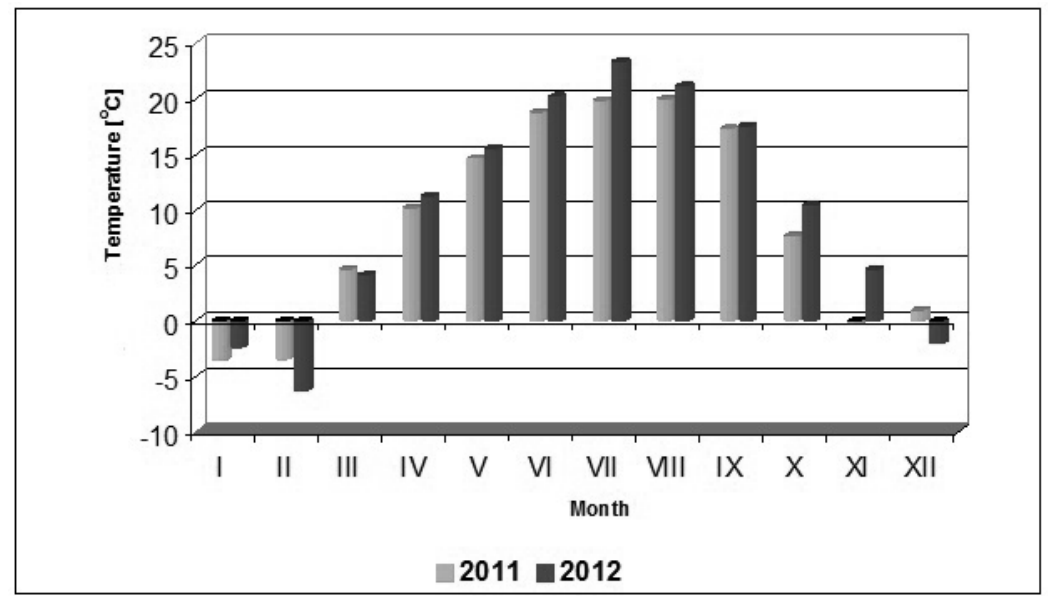

Fig. 7. Average monthly air temperature $\left({ }^{\circ} \mathrm{C}\right)$, MS Cluj-Napoca $(2011,2012)$

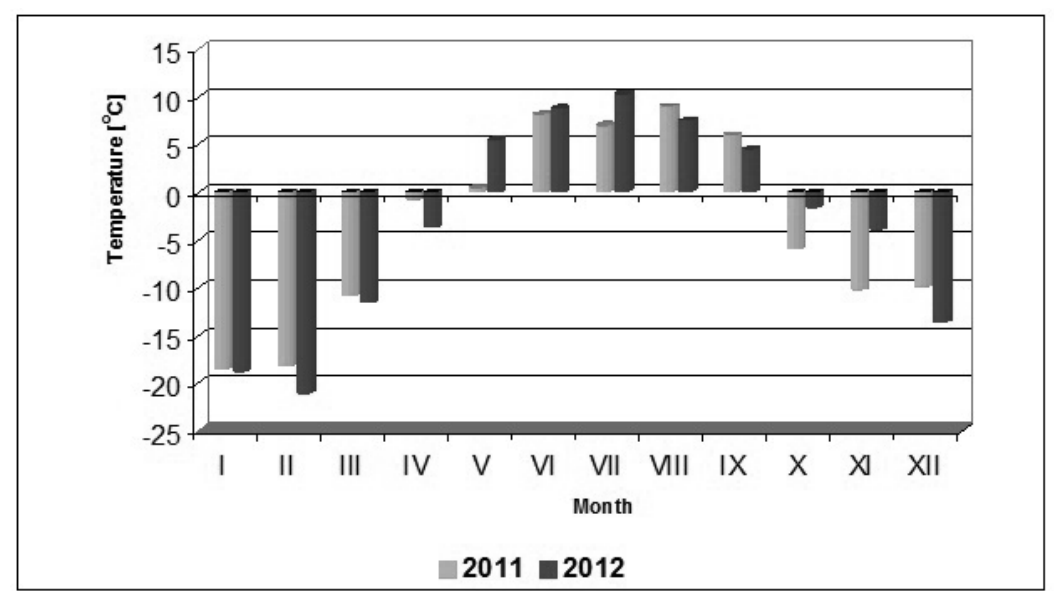

Fig. 8. Minimum monthly air temperature $\left({ }^{\circ} \mathrm{C}\right)$, MS Cluj-Napoca $(2011,2012)$

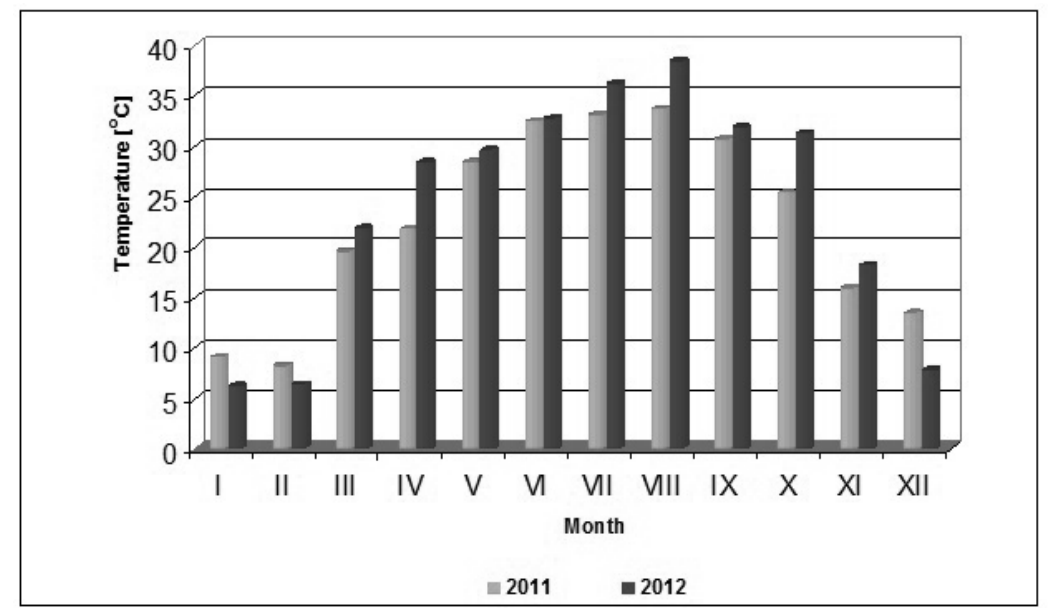

Fig. 9. Maximum monthly air temperature $\left({ }^{\circ} \mathrm{C}\right)$, MS Cluj-Napoca $(2011,2012)$ 
Direction of the slope water drainage affects the excess moisture, because depending on the slope, soil type, soil texture and the existing vegetation is influenced the infiltration rate of water into the soil.

Water drainage direction map (Fig. 10) shows the areas crossed by the valleys of the rivers and streams, which is shed directly or indirectly into Someş Mic and the collector flow direction the higher zone to lower zone. Also, the soil map (Fig. 11) highlights that in the Somess Mic meadow the soils are alluvial, the mother rock is the alluvial gravel, resting on a compact marl formation with inserts of tuffs.

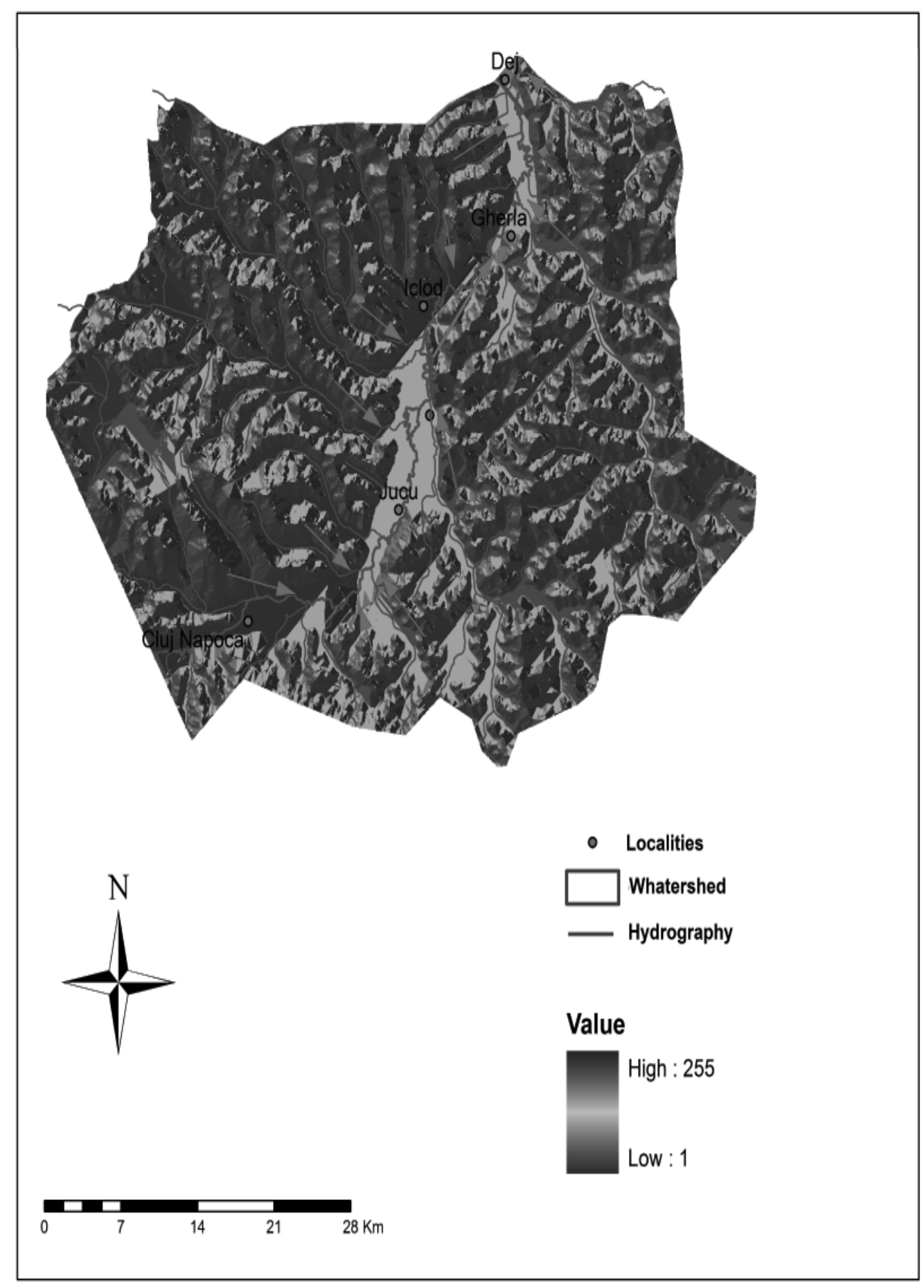

Fig. 10. Direction of the water drainage on the slope for Someș Mic between Cluj-Napoca and Dej 


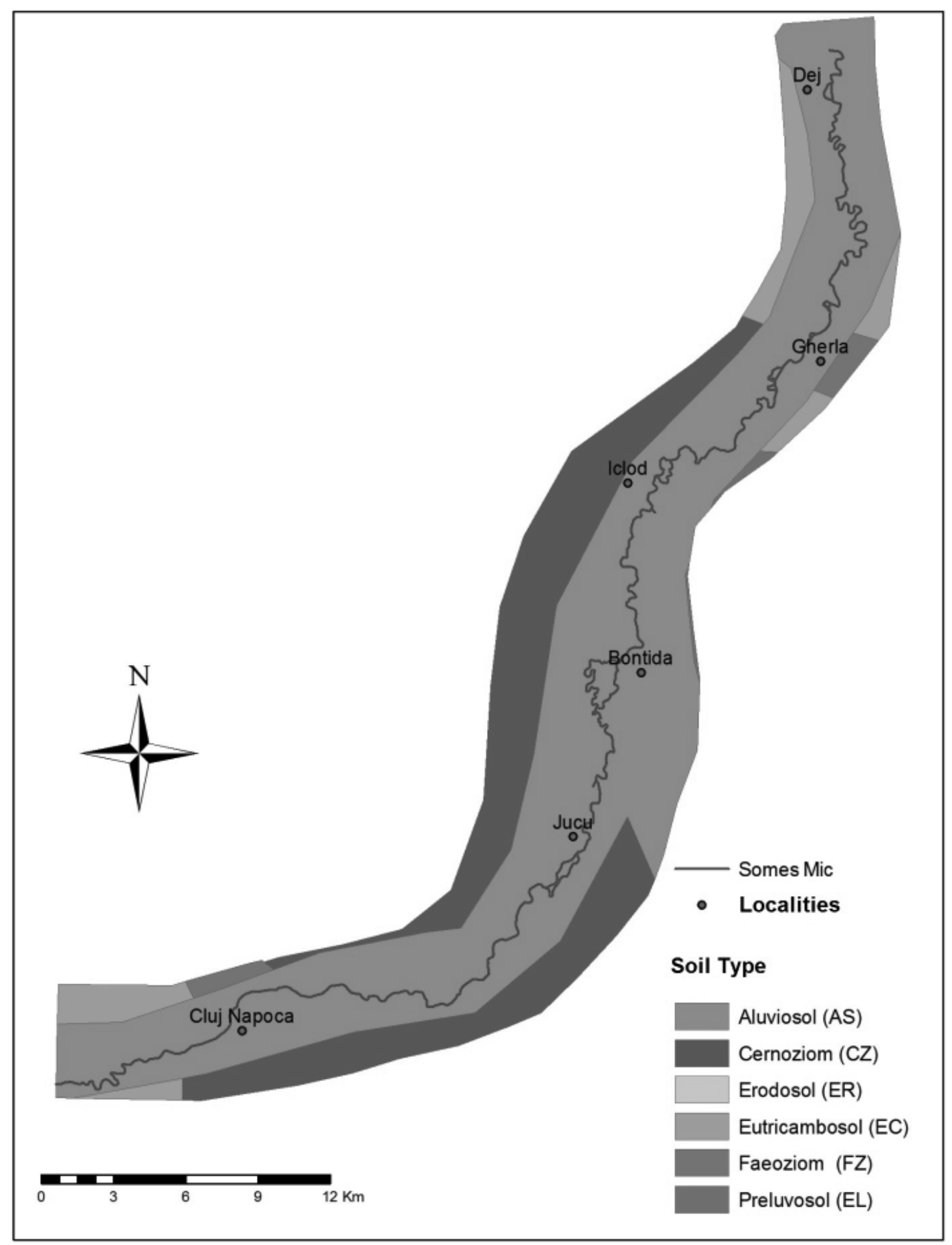

Fig. 11. Soil map for Someș Mic meadow between Cluj-Napoca and Dej

These maps and the database behind them are extremely useful if it is wanted to create or rehabilitate a complex hydrological system enabling maximum exploitation of the potential of these lands, taking into account that in the studied area the type of culture varies from cereals (Fig. 12 $a$ and $b$ ) to cultivated vegetables in protected areas or in the field (Fig. $12 \mathrm{c}$ and d). 


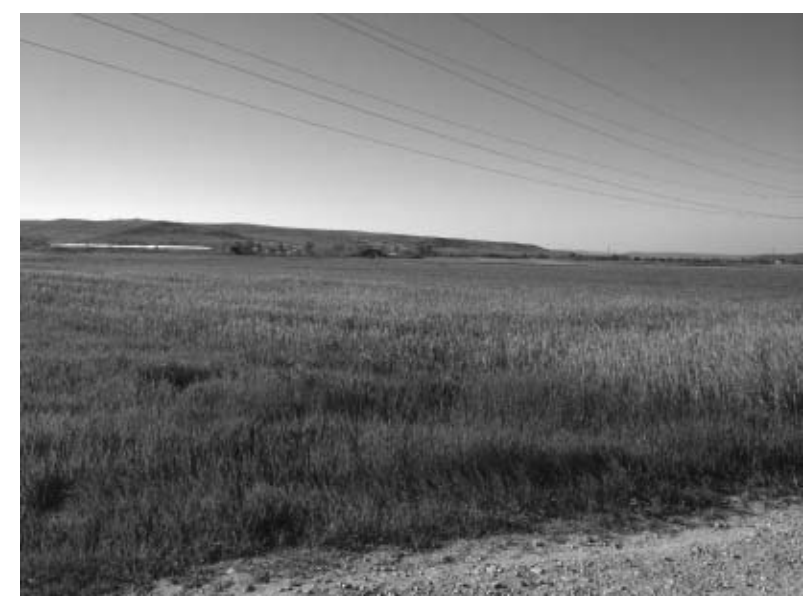

a.

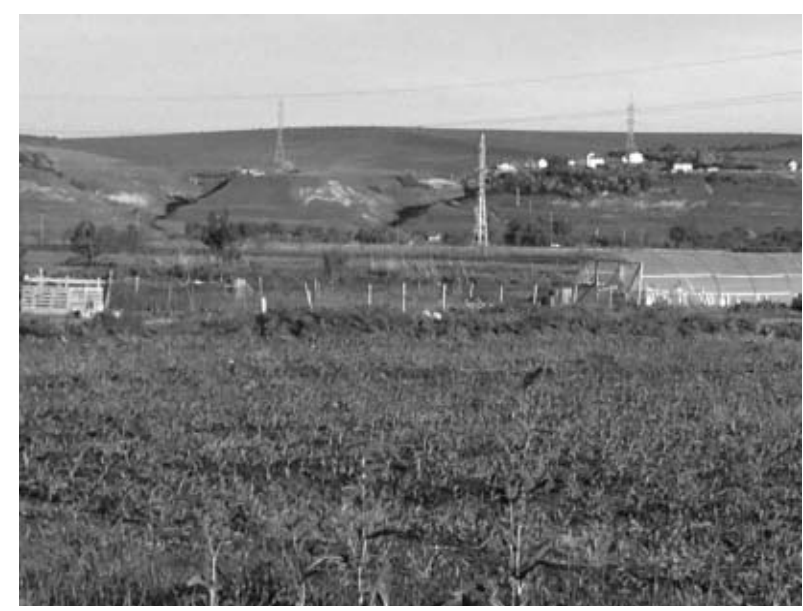

C.

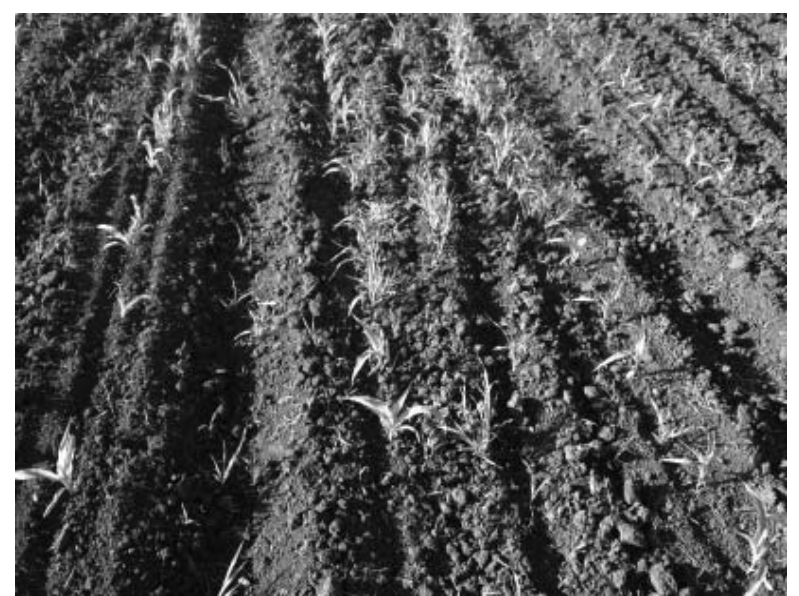

b.

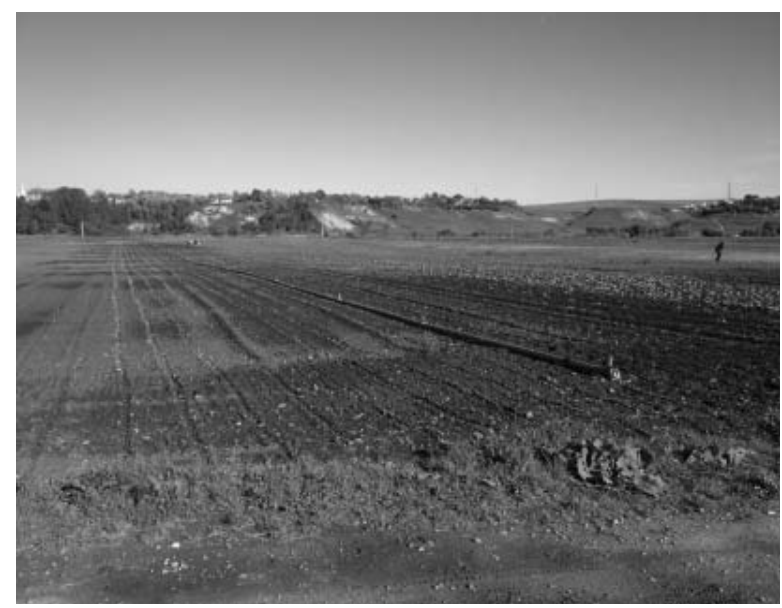

d

Fig. 12. Type of crops cultivated in the studied area

\section{CONCLUSION}

This thematic interdisciplinary paper aims to highlight the issues of combating and preventing degradation processes of floodplain agricultural ecosystems from Someș Mic meadow, between Cluj-Napoca and Dej, caused by excess water from the soil.

Through this paper is intended to highlight the need to develop management strategies and management of land improvement works in order to provide transparency from one level to another (farmer - state institutions and vice versa) through awareness of of all actors involved that the resources of water must be used efficiently.

In the future to obtain a comprehensive understanding of the activities to combat and prevent excess moisture from the soil surface and the soil can create web-based applications that can be configured to meet the needs of this area of research by the ability use live feeds, automated analysis and alert tools.

Using Geographic Information System facilitates a better and a more efficient decision making of field operations, having the possibility of permanently updating field data.

Acknowledgments: This paper was published under the frame of European Social Fund, Human Resources Development Operational Programme 2007-2013, projectno. POSDRU/159/1.5/S/132765. 


\section{REFERENCES}

1. Borșan T. and G. E. Voicu (2009). Sisteme informaționale geografice - Îndrumător de laborator, Seria didactică, Ed. Universității “1 Decembrie 1918”, Alba Iulia.

2. Dîrja M. and V. Budiu (2006). Îmbunătățiri funciare combaterea excesului de umiditate pe terenurile agricole, Ed. Academic Pres, Cluj-Napoca.

3. Dimitriu G. (2007). Sisteme informatice geografice (GIS), Ed. Albastră, Cluj-Napoca.

4. Guș P. and T. Rusu (2011). Unconventional Soil Tillage Systems, Agrotechnical and Economical Alternative for Durable Agriculture, Soil Minimum Tillage Systems $6^{\text {th }}$ International Symposium, Ed. Risoprint, Cluj-Napoca.

5. Imbroane A. M. and D. Moore (1999). Inițiere în GIS și teledetecție, Ed. Presa Universitară Clujeană, Cluj-Napoca.

6. Legin E. K., Yu. I. Trifonov, M. L. Khokhlov, D. N. Suglobov and E. E. Legina (2007). Dynamics of Gleyzation-Mediated Leaching of Radiostrontium from Soils, Radiochemistry, vol. 49, no. 2, Pleiades Publishing.

7. Moga I., Lenuța Drăgan and C. Răducanu (2007). Cercetări privind agrotehnica plantelor furajere la Fundulea și în rețeaua experimentală, Agrotehnica culturilor, An. I.N.C.D.A. Fundulea, vol. LXXV, volum Jubiliar.
8. Munteanu Gh. C. (2003). Cartografie matematică, Ed. Matrix Rom, București.

9. Oncu M. and S. Bilasco (2010). Valea Sebeșului Considerații Biopedogeografice, Geografia Napocensis Anul IV, nr. 1, Cluj-Napoca.

10. Palamariu M. (2004), Cartografie și geodezie - Aplicații, Ed. Risoprint, Cluj-Napoca

11. Păcurar I. and M. Buta (2007). Pedologie și bonitarea terenurilor agricole - lucrări practice, Ed. Academic Pres, Cluj-Napoca.

12. Păcurar I., S. Bilasco, C. M. Cristina, M. Dîrja, Ioana Claudia Moldovan, H. M. Păcurar and A. Lucaci (2013). Research on Identification of Degraded Lands in Transilvanian Plateau Using GIS Spatial Analysis, ProEnvironment, Journal of Documentation, Research and Professional Training, vol.6, No.14, Ed. Bioflux, Cluj-Napoca.

13. Pidwirny M. (2010). Soil, Encyclopedia of Earth, www. eoearth.org updated 21 February 2013.

14. Popescu C. and D. Bucur (2004). Valorificarea unor terenuri agricole expuse poluării și degradării, Ed. Ion Ionescu de la Brad, Iași. 